\title{
Article \\ Randomized Estimation of the Net Present Value of a Residential Housing Development
}

\author{
Tadeusz Kasprowicz $^{1}\left[\begin{array}{l}\text {, } \\ \text {, Anna Starczyk-Kołbyk }\end{array}\right.$ \\ 1 Faculty of Civil Engineering and Geodesy, Military University of Technology, ul. gen. Sylwestra Kaliskiego 2, \\ 00-908 Warsaw, Poland; tadeusz.kasprowicz@wat.edu.pl \\ 2 PFR Nieruchomości S.A., Polish Development Fund Group, ul. 6 Przeskok Str., 00-032 Warsaw, Poland; \\ robertwojcik63@gmail.com \\ * Correspondence: anna.starczyk@wat.edu.pl
}

Citation: Kasprowicz, T.;

Starczyk-Kołbyk, A.; Wójcik, R. Randomized Estimation of the Net

Present Value of a Residential

Housing Development. Appl. Sci.

2022, 12, 124. https://doi.org/

10.3390/app12010124

Academic Editors: Mariusz Szóstak, Marek Sawicki and Jarosław Konior

Received: 22 October 2021

Accepted: 20 December 2021

Published: 23 December 2021

Publisher's Note: MDPI stays neutral with regard to jurisdictional claims in published maps and institutional affiliations.

Copyright: (C) 2021 by the authors. Licensee MDPI, Basel, Switzerland. This article is an open access article distributed under the terms and conditions of the Creative Commons Attribution (CC BY) license (https:// creativecommons.org/licenses/by/ $4.0 /)$.

\begin{abstract}
Randomized estimation of the net present value of a housing development allows for the assessment of the efficiency of projects in random implementation conditions. The efficiency of a project is estimated on the basis of primary input data, usually used in project planning. For this purpose, random disturbances are identified that may randomly affect the course and results of the project. The probability and severity of disturbances are determined. The primary initial data is then randomized, and a randomized probabilistic index of the project's net present value is calculated, the value of which indicates whether the project is profitable or whether implementation should be stopped. Based on this data, the expected total revenue, the expected total cost, the expected gross profit, and the net present value of the randomized performance of the project are calculated. The values of these are estimated for expected, favorable, and unfavorable conditions of implementation. Finally, the risks for the total revenue and total cost of the project are calculated and plotted for comparative revenue values in the range $[1,0]$ and cost in the range $[0,1]$. Their analysis makes it possible to make the right investment decisions before starting the investment at the preparation stage.
\end{abstract}

Keywords: efficiency; risk; randomization; construction project

\section{Introduction}

The term efficiency [1-5] in a general sense describes the achievement of objectives in an economic manner. It is a search for a good balance between the resources used (time, money, space, equipment, and materials) and the achievement of the objectives of the activity [6].

The term efficiency is a measurable concept that can be applied to the quantitative assessment of production or performance when a given number of resources (money, time, work, etc.) has been used. All well-known methods of assessing efficiency, although they consider the time value of money, actually use deterministic data. The results obtained in this way are also deterministic. In such cases, the efficiency is usually measured as the ratio of useful result ("product") to total outlay. It can be expressed with the mathematical formula $\mathrm{E}=\mathrm{P} / \mathrm{C}$ that is the ratio of the amount $\mathrm{P}$ of useful result (benefit) of project implementation to the amount (cost) $\mathrm{C}$ of consumed resources.

Generally, these indicators are reliable and well describe efficiency when the project would be implemented in stable and balanced economic and environmental conditions. Usually, inner and outer random events can strongly affect the project implementation. Such disturbances can increase costs and decrease revenues of the project $[7,8]$.

In published books and papers relevant to the project lifecycle, problems predominate the deterministic approach, for example: Kasprowicz, T. (2015) [9] or Kasprowicz T. (2011) [10] and Bizon-Górecka, J. (2008) [11]. 
However, because of random conditions of project implementation, the better approach is probabilistic analysis when the efficiency of the project implementation can be characterized as a random variable.

The term of risk (probabilistic conditions) means that a situation in which the result of the project is unknown, uncertain, or there is a possibility that something will succeed or fail, and the probability of the random events appearance and project execution according to the plan is known or it can be estimated. These problems have been studied by Cao, J., Song, W. 2016 [12], Radło M. J. 2015 [13], Kalkhoran S. H. A., Liravi, G., Rezagholi F. 2014 [14], Stephen C Ward, S. C., and Chris B Chapman, Ch. B. 1995 [15], et al. Here, the risk conditions describe circumstances in which individual capabilities and benefits associated with each possible action within the project are known or can be predicted with some probability - the probability of possible conditions of the project implementation is known or can be reliably estimated. In the conditions of risk variability, different random disturbances can interfere with the process of project implementation. In the aftermath of these disturbances, the impact variability of technical, technological, social, economic, and environmental random factors can impede or preclude the project accomplishment according to the design documentation and technical specification of the works execution and acceptance [16].

These may randomly increase prices and consumption of labor and resources, expenditures of machinery and equipment and reduce the productivity of project executors.

So, in random conditions, the efficiency is a random variable and must be estimated, taking into account the impact of random disturbances on course and results of the project lifecycle implementation $[17,18]$.

This is a process of creating random variables of costs and revenues as well as connected and derived quantities that reflect likely random conditions of the construction project's implementation. Based on the randomized data, the proposed method of estimating the net present value of the construction project's efficiency can be estimated. The method should be applied when random disturbances can disturb or disrupt the project implementation. That is, in a situation, during the project implementation there are likely disturbances that can randomly change the cost, time, and quality of projects.

The method of assessing the effectiveness of unstable construction projects in the conditions of the impact of significant disturbances on the course and results of implementation uses specific concepts and mathematical formulas in a different scope and at different stages of the investment.

The end result of the presented method is a reliable estimation of profitability and a realistic assessment of the cost-benefit balance of unstable construction projects already at the planning stage.

Often, a distinction is made between economic and technical efficiency. Economic efficiency means producing and distributing goods at the lowest possible cost. Technical efficiency means the maximum amount of production for a given input, or the maximum amount of an output that can be obtained from a certain input.

In many studies, the term "efficiency" is often used to evaluate economic activities (Blue Book, [19]). From this point of view, economic and financial efficiency are most often distinguished.

The randomized method for estimating the net present value of a construction project's efficiency has been worked out recently. The method has been theoretically finished and verified on simple examples of projects. However, the method is still being tested and verified in the process of estimating the net present value of the housing investment's efficiency.

So, the objective of the research was to verify the correct probabilistic method for the analysis and assessment of the net present value of the effectiveness of unstable construction projects for real building investments.

In the article, research results for real building investments by the randomized method of the estimation of construction projects' efficiency are presented. 
Such building investments have been realized by a developer in Warsaw, the capital city of Poland. Here, the randomized method of efficiency estimating of the net present value of one such residential housing development's efficiency is presented.

The subject of the study is one of the stages of a five-stage construction of a residential housing development in Warsaw. The settlement was built by a Warsaw real estate developer. The development area takes up approximately 1.3 hectares of land. Inside this area, six multi-family buildings of different size, set on a single garage plate, have been built. Complete with the buildings, some concomitant facilities have been built, for example, new public roads, additional parking spaces, and usable premises. The residential housing development has been built in the system of a general contractor. Implementation cycle of the project consisted of four basic stages, namely: feasibility study (6 months), designing (12 months), construction (18 months), and operation and maintenance (60 months). However, the stage of operation and maintenance concerned only activities resulting from the general guarantee and warranty for defects. The efficiency analysis was carried out as part of the feasibility study. In the first stage of the analysis, the project life cycle was projected, i.e., the stages of implementation and tasks cost of these stages, as well as tranches of revenue payments. Moreover, in this stage, discount rates were established, and the types of random disturbances of the project implementation were determined. In the case of this project, the primary initial data were developed collectively by the team for the real estate purchases and the team for analysis and preparation of investments. The teams identified and estimated this data, taking into account the predicted conditions and projected prices in the country for the entire project lifecycle implementation. The discount rate was determined on the basis of historical data of the investments realized by the developer and accordingly to the current market forecasts. The investment in the initial phase, such as all investments of this company, was financed by an operating loan for the activities of the developer. The first and second tranches of payment were flown in with the start of sales of the first and second parts of the apartments, respectively. The third and fourth tranches of revenue payments began with the start of sales of concomitant facilities, such as parking lots and commercial premises. Detailed tally of the project cost and revenue was shown in spreadsheets later in the case study. In random implementation conditions, costs and revenues of the project can be disturbed by random disturbances. Such cost random disturbances have been defined in accordance with conditions and requirements of the project stages and tasks implementation, whereas revenue random disturbances have been projected in accordance with likely prices on domestic and foreign property markets, as well as conditions and quality of business environment. Unfortunately, until now, the impact of the disturbances on the course and results of the project was analyzed mostly qualitatively. In this way, both costs and revenues were estimated approximately only on the basis of experience and knowledge of the analysts. The company has not used yet any probabilistic method that would have allowed quantitative analysis and estimation of costs and revenues when random disturbances may have an impact on the project implementation. The randomized method of estimation of the net present value of a construction project's efficiency were developed in order to bridge this gap. It is assumed that such an analysis would be carried out in the "feasibility study" stage and could be used by teams that are also currently involved in the planning of construction projects.

\section{Materials and Methods}

Estimation of the primary initial data is the first phase of the randomized estimation of the net present value of the residential housing development's efficiency. These data are the basis for further analysis and data randomization for the estimation of efficiency. They directly describe the kinds and values of parameters and characteristics of the project implementation. In the primary analysis, based on an in-depth analysis of the facilities structure and the construction conditions, the residential housing development implementation cycle has to be projected. Such a lifecycle has been defined in a similar way by De Wilde, P. 2018 [20], Ding, L., Zhou, Y., Akinci, B. 2014 [21], Halpin, D. W., 
Woodhead R. W. 1998 [22], Ritz, G., 1994 [23], et al. In this meaning, the construction project lifecycle consisted of several successive stages $s=1,2, \ldots, t$. In each stage, the subset $A^{s}$ of tasks $a_{i}$ should be executed, $A^{s}=\left\{a_{i}: i=1,2, \ldots, i^{s}\right\}$. During the project lifecycle implementation, the set $A$ of all tasks $a_{i}$ of the project should be carried out, $A=\left\{A^{s}: s=1,2, \ldots, t\right\}=\left\{a_{i}: i=1,2, \ldots, i^{a}\right\}$. Consistently, for each subset $A^{s}$ of tasks $a_{i}$, the subset $C^{s}$ of the initial preliminary execution costs $c_{i}$ should be estimated, $C^{s}=\left\{c_{i}: i=1,2, \ldots, i^{s}\right\}$. In this way, the subsets $C^{s}, s=1,2, \ldots t$, contain all costs $c_{i}$, and each stage $s$, of the project and form the set $C=\left\{C^{s}: s=1,2, \ldots, t\right\}=\left\{c_{i}: i=1,2, \ldots, i^{t}\right\}$. According to the stage of construction, the apartments and other facilities can be sold after some objects are finished, or they can be sold after the whole residential housing development' completion. Each sold part represents one tranche $b_{i}$ of revenue $p_{i}, i=1,2, \ldots, i^{b}$. All paid tranches $b_{i}$ of revenues $p_{i}$ constitute the set $P=\left\{p_{i}: i=1,2, \ldots, i^{b}\right\}$. Because of money value changes in time, for both costs and revenues discount rates, $\rho_{i}$ paid per year should be set.

The primary initial data of costs for the residential housing development implementation cycle can be determined as follows:

1. Stages $s$ and subsets $A^{s}$ of task $a_{i}$, and subsets $C^{s}$ of cost $c_{i}$ :

feasibility study-s1, the subset $A^{1}$ of tasks $a_{i}, A^{1}=\left\{a_{i}, i=\overline{1,5}\right\}$ and the subset $C^{1}=\left\{c_{i}: i=\overline{1,5}\right\}$ of costs $c_{i}$ :

$a_{1}$-initial analysis and its cost $c_{1}$.

$a_{2}$-land acquisition and its cost $c_{2}$.

$a_{3}$-determination of the technical conditions and its cost $c_{3}$.

$a_{4}$ - coverage of overheads and its cost $c_{4}$.

$a_{5}$-tracing of economic and financial conditions and its cost $c_{5}$;

design documentation development-s2, the subset $A^{2}$ of tasks $a_{i}, A^{2}=\left\{a_{i}, i=\overline{1,6}\right\}$ and the subset $C^{2}=\left\{c_{i}: i=\overline{1,6}\right\}$ of costs $c_{i}$ :

$a_{1}$-initial concept and nets and their cost $c_{1}$.

$a_{2}$ - conceptual architectural design and its cost $c_{2}$.

$a_{3}$ - general conceptual design and its $\operatorname{cost} c_{3}$.

$a_{4}$ - construction project and its cost $c_{4}$.

$a_{5}$-detailed design (executive project) and its cost $c_{5}$.

$a_{6}$ - complementary design documentation and its cost $c_{6}$;

construction-s3, the subset $A^{3}$ of tasks $a_{i}, A^{3}=\left\{a_{i}, i=\overline{1,8}\right\}$ and the subset $C^{3}=\left\{c_{i}: i=\overline{1,8}\right\}$ of costs $c_{i}$ :

$a_{1}$ - construction site development and its cost $c_{1}$.

$a_{2}$-structure of construction, state zero, and its cost $c_{2}$.

$a_{3}$ - plumbing and electrical wiring, state zero, and its cost $c_{3}$.

$a_{4}$-structure of construction-superstructure and its cost $c_{4}$.

$a_{5}$ - plumbing and electrical wiring - superstructure and its $\operatorname{cost} c_{5}$.

$a_{6}$ - nets and connections to main supply and their cost $c_{6}$.

$a_{7}$-roads and land development and decorative green and their cost $c_{7}$.

$a_{8}$ - technological startup of construction and its cost $c_{8}$;

operation and maintenance-s 4 , the subset $A^{4}$ of tasks $a_{i}, A^{4}=\left\{a_{i}, i=\overline{1,3}\right\}$ and the subset $C^{4}=\left\{c_{i}: i=\overline{1,3}\right\}$ of $\operatorname{costs} c_{i}$ :

$a_{1}$-unpredicted additional completion activities and their cost $c_{1}$.

$a_{2}$-additional activities under contract warranty and their $\operatorname{cost} c_{2}$.

$a_{3}$-maintenance of flats unsold according to the plan and its $\operatorname{cost} c_{3}$ :

2. The set $A$ of subsets $A^{s}, A=\left\{A^{s}: s=\overline{1,4}\right\}=\left\{a_{i}: i=\overline{1,22}\right\}$.

3. Discount rates $\rho_{i}$ paid per year $\tau$ during the period of incurring costs.

4. The set $C$ of subsets $C^{s}, C=\left\{C^{s}: s=\overline{1,4}\right\}=\left\{c_{i}: i=\overline{1,22}\right\}$. 
The basic primary initial data of revenue for the residential housing development implementation cycle can be determined as follows:

1. The set $\mathrm{B}$ of tranches $b_{i}$ and the set $P$ of the revenues $p_{i}, B=\left\{b_{i}: i=\overline{1,4}\right\}$, $P=\left\{p_{i}: i=\overline{1,4}\right\}$ :

$b_{1}$ - sale of apartments-part 1 and revenue $p_{1}$.

$b_{2}$ - sale of apartments-part 2 and revenue $p_{2}$.

$b_{3}$-sale of parking lots and revenue $p_{3}$.

$b_{4}$-sale od usable premises and revenue $p_{4}$.

2. Discount rates $\rho_{i}$ paid per year $\tau$ for revenues $p_{i}, i=\overline{1,4}$.

In the case of the residential housing development implementation, the primary initial data for costs have been listed in Table 1 and for revenues in the Table 2 in the chapter Results.

Table 1. Primary initial data for costs.

\begin{tabular}{|c|c|c|c|c|c|c|}
\hline Stages $s$ & $a_{i} \in A^{s}$ & $a_{i} \in A$ & $\begin{array}{c}c_{i} \\
\text { PLN }\end{array}$ & $\rho_{i} \%$ & Years for $\rho_{i}$ & $\begin{array}{c}K_{i} \\
\text { PLN }\end{array}$ \\
\hline \multirow{5}{*}{ s1 } & $a_{1}$ & $a_{1}$ & 100,000 & 3 & 0.6 & 98,242 \\
\hline & $a_{2}$ & $a_{2}$ & $12,300,000$ & 3 & 0.6 & $12,083,779$ \\
\hline & $a_{3}$ & $a_{3}$ & $3,500,000$ & 3 & 0.6 & $3,438,474$ \\
\hline & $a_{4}$ & $a_{4}$ & $6,400,000$ & 3 & 0.6 & $6,287,495$ \\
\hline & $a_{5}$ & $a_{5}$ & $3,400,000$ & 3 & 0.6 & $3,340,232$ \\
\hline \multirow{6}{*}{$s 2$} & $a_{1}$ & $a_{6}$ & 200,000 & 4 & 1.5 & $1,885,732$ \\
\hline & $a_{2}$ & $a_{7}$ & 200,000 & 4 & 1.5 & 188,573 \\
\hline & $a_{3}$ & $a_{8}$ & 200,000 & 4 & 1.5 & 188,573 \\
\hline & $a_{4}$ & $a_{9}$ & 600,000 & 4 & 1.5 & 565,720 \\
\hline & $a_{5}$ & $a_{10}$ & 600,000 & 4 & 1.5 & 565,720 \\
\hline & $a_{6}$ & $a_{11}$ & 200,000 & 4 & 1.5 & 188,573 \\
\hline \multirow{8}{*}{ s3 } & $a_{1}$ & $a_{12}$ & 200,000 & 4 & 3 & 177,799 \\
\hline & $a_{2}$ & $a_{13}$ & $10,500,000$ & 4 & 3 & $9,334,462$ \\
\hline & $a_{3}$ & $a_{14}$ & $3,500,000$ & 4 & 3 & $3,111,487$ \\
\hline & $a_{4}$ & $a_{15}$ & $16,500,000$ & 4 & 3 & $14,668,440$ \\
\hline & $a_{5}$ & $a_{16}$ & $3,500,000$ & 4 & 3 & $3,111,487$ \\
\hline & $a_{6}$ & $a_{17}$ & $3,950,000$ & 4 & 3 & $3,511,536$ \\
\hline & $a_{7}$ & $a_{18}$ & $1,000,000$ & 4 & 3 & 888,996 \\
\hline & $a_{8}$ & $a_{19}$ & 500,000 & 4 & 3 & 444,498 \\
\hline \multirow{4}{*}{$s 4$} & $a_{1}$ & $a_{20}$ & 100,000 & 4 & 3 & 88,900 \\
\hline & $a_{2}$ & $a_{21}$ & 200,000 & 4 & 6 & 158,063 \\
\hline & $a_{3}$ & $a_{22}$ & 150,000 & 4 & 5 & 123,289 \\
\hline & Sum & $\begin{array}{l}\text { Total } \\
\text { primary } \\
\text { cost }\end{array}$ & $67,800,000$ & \multicolumn{2}{|c|}{$\begin{array}{l}\text { Discounted total } \\
\text { primary cost }\end{array}$} & $62,752,911$ \\
\hline
\end{tabular}

Table 2. Primary initial data of revenues.

\begin{tabular}{cccccc}
\hline \multirow{2}{*}{ Revenue } & $\boldsymbol{b}_{\boldsymbol{i}} \in \boldsymbol{B}$ & $\begin{array}{c}\boldsymbol{p}_{\boldsymbol{i}} \\
\text { PLN }\end{array}$ & $\boldsymbol{\rho}_{\boldsymbol{i}} \%$ & Years for $\boldsymbol{\rho}_{\boldsymbol{i}}$ & $\begin{array}{c}\boldsymbol{D} \boldsymbol{i} \\
\text { PLN }\end{array}$ \\
\hline \multirow{3}{*}{ Tranches } & $b_{1}$ & $11,100,000$ & 4 & 3 & $9,867,860$ \\
& $b_{2}$ & $68,900,000$ & 4 & 5 & $56,630,778$ \\
& $b_{3}$ & $6,200,000$ & 4 & 5 & $5,095,948$ \\
& $b_{4}$ & $4,100,000$ & 4 & 4 & $3,504,697$ \\
\hline \multirow{2}{*}{ Sum } & Overall revenue & $90,300,000$ & Discounted overall revenue & $75,099,282$ \\
\hline
\end{tabular}

In Tables 1 and 2, project primary initial costs $c_{i}$ and revenues $p_{i}$ were discounted by the use of formulas $K_{i}=\frac{c_{i}}{\left(1+\rho_{i}\right)^{\tau}}$ and $D_{i}=\frac{p_{i}}{\left(1+\rho_{i}\right)^{\tau}}$, respectively. In this way, one can define the set $\mathcal{K}=\left\{K_{i}: i=1,2, \ldots, i^{t}\right\}=\left\{K_{i}: i=\overline{1,22}\right\}$ of discounted costs $K_{i}$ of tasks $a_{i}$ 
execution and the set $\mathcal{D}=\left\{D_{i}, i=1,2, \ldots, i^{b}\right\}=\left\{D_{i}, i=\overline{1,4}\right\}$ of discounted revenues $D_{i}$ paid in tranches $b_{i}$.

The primary initial data describe project implementation without taking into account likely influences of random events on the course and results of the project. In practice, it can cause incorrect estimation of the costs and revenues of the project. In order to take cognizance of such disturbances, the primary initial data must be randomized.

\subsection{Randomization of the Primary Initial Data}

2.1.1. Estimation of the Impact of Disturbances on the Task's Costs and the Revenues Tranches

Here, randomization means transforming the deterministic primary initial data into probabilistic computing data. Such modification should be undertaken when future random inner and outer disturbances can significantly impact and change the values of project costs and revenues. This is a process of creating random variables that reflect likely random conditions of the project implementation. In this area, the issues of costs that must be incurred on a project task's execution and questions of revenues that should be paid in tranches for the completed tasks have to be analyzed.

As part of the cost analysis, it is necessary to analyze probabilistic characteristics of cost random variables depending on internal and external random disturbances related to the cost of project tasks implementation. In the considered situation, the sets $A^{s}, s=\overline{1, t}$, of tasks $a_{i}$ may be disturbed by relevant sets $E^{s}$ of disturbances $e_{i, j}$, $E^{s}=\left\{e_{i, j}: i=1,2, \ldots, i^{s}, j=1,2, \ldots, j^{s}\right\}$. In the result, costs $K_{i}$ of tasks $a_{i}$ may randomly change. In the analyzed case, the sets $E^{s}$ as well as disturbances $e_{i, j}$ that belong to them are relatively independent of each other. Each set $E^{S}$ of disturbances $e_{i, j}$ correspond with a particular stage $\mathrm{s}$. This means that the execution of each task $a_{i} \in A^{s}$ may be randomly affected by each threat $e_{i, j} \in E^{s}$. All disturbances of costs must be identified for projected places, environment, and system surroundings of the project.

For the residential housing development sets $E^{s}=\left\{e_{i, j}: i=\overline{1, i^{s}}, j=\overline{1, j^{s}}\right\}, s=\overline{1,4}$, of disturbances $e_{i, j}$ related to sets $A^{s}=\left\{a_{i}: i=1, i^{s}\right\}$ of tasks $a_{i}$ have been identified as follows:

Stage of feasibility study- $S=1, A^{1}=\left\{a_{i}: i=\overline{1,5}\right\} . E^{1}=\left\{e_{i, j}: i=\overline{1,5}, j=\overline{1,6}\right\}:$

1. Modification of the terms of financing operational analysis $j=1$-costs of additional:

- general re-analysis and complementary research;

- land pre-purchasing analysis, soil property tests, checking soil pollution and possible protections, as well as the risk of land purchase costs and the final purchase price;

- commissions for intermediaries and often remediation;

- $\quad$ expertise and structural survey of existing buildings to be secured;

- evaluation of the scale and size of the existing paid land rights, land servitude, and/or transit for gestors, etc.

2. Architectural survey-incorrect description of the scope of the reconstruction $j=2$ :

- extra costs of additional analyzing and assessing of the type and scope of reconstruction of existing infrastructure.

3. Technical conditions of connecting utilities differ significantly from assumptions $j=3$ :

- additional costs of re-analysis of technical conditions for connection to the system of utilities, e.g., water supply and sewerage, energy, communication technology, gas, etc., can significantly change costs of the project.

4. Reconstruction of the collision of the technical infrastructure in a much expanded, unpredicted range $j=4$ :

- extra costs of re-analysis, redesign, and reconstruction of the technical infrastructure because of analytical errors or unpredicted changings of conditions or circumstances. 
5. Analysis of the absorbency of terrain incompatible with possible to obtain of development $j=5$ :

- additional costs of re-analysis of possible construction permit and redesign of terrain absorbency.

6. Changings of overall economic and business conditions $j=6$ :

- possible direct changes of any costs of management, administrative staff, and all other employees.

Stage of design documentation development $-s=2, A^{2}=\left\{a_{i}: i=\overline{1,6}\right\}$, $E^{2}=\left\{e_{i, j}: i=\overline{1,6}, j=\overline{1,6}\right\}$ :

1. Collapse of the design office $j=1$ :

- costs of searching and a contract negotiation with a new design office;

- additional costs of development of new design documentations.

2. Modification of the rules of law or delivery system $j=2$ :

- additional costs of modification of design details caused by changes in the rules of law, or technical or organizational requirements during design.

3. Collapse of the housing sales market $j=3$ :

- it can be forced to completely redesign the investment and change the structure of apartments or even the standard of investment so that it is adapted to the current demand of the real estate market.

4. Changes of technical standards $j=4$ :

- cost of implementation of a new technology;

- additional costs of re-design and development of partly new design documentation.

5. Changes of overall economic and business conditions $j=5$ :

- it is possible to directly change any costs of management, administrative staff, strictly design personnel, and all others, as well as the work of machines and auxiliary equipment.

Stage of construction $-s=3, A^{3}=\left\{a_{i}: i=\overline{1,8}\right\}, E^{3}=\left\{e_{i, j}: i=\overline{1,8}, j=\overline{1,5}\right\}:$

1. Change in prices of goods and services:

- Changes in the purchasing costs of goods and services.

2. Collapse of the services market of construction:

- additional costs of likely delay of activities and obtaining contractors.

3. Collapse of the project's general contractor:

- costs of searching for and a contract negotiation with a new contractor;

- re-employment of the new contractor, beginning of works continuation.

4. Particularly unfavorable conditions for the implementation of works:

- possible disturbances of individual outer works;

- extra costs of likely delay of work implementation and other activities;

- there are possible direct changes of any costs of employment of managerial staff, core workers, and auxiliary workers, as well as work of machines and auxiliary equipment.

5. Changings of economic and business conditions and deterioration of payment terms: Stage of operation and maintenance $-s=4, A^{4}=\left\{a_{i}: i=\overline{1,3}\right\}, E^{4}=\left\{e_{i, j}: i=\overline{1,3}\right.$, $j=\overline{1,5}\}$ :

1. Disclosure of hidden defects and removal of them within the product warranty or warranty for physical defects $j=1$ :

- additional activities and costs related to removing hidden defects and faults (at the expense of the developer). 
2. Maintenance of unsold homes (apartments, usable premises, parking lots, etc.) significantly exceeding budgetary assumptions $j=2$ :

- extending time and additional cost of maintenance (at the expense of the developer).

3. Supplementary activities of construction completion-beyond the contract with the project's general contractor $j=3$ :

- additional costs of the construction completion-beyond the contract with the project's general contractor (at the expense of the developer).

4. Changes of economic and business conditions and deterioration of payment terms $j=4$ :

- there are possible direct changes of any costs of employment, core workers, auxiliary workers, the work of machines and auxiliary equipment, as well as goods and services.

5. Litigation and legal proceedings $j=5$ :

- additional costs of litigation and legal proceedings;

- additional costs related to the extension of maintenance of unsold homes and other higher costs.

As part of the revenue analysis, it is necessary to analyze probabilistic characteristics of revenue random variables depending on internal and external random disturbances related to the payment of revenues tranches. The random disturbances of revenues reflect the influence of likely random conditions that may exist in a given place, environment, or systemic situation. They also depend on financial market stability during the project implementation and revenue payment. Taking all mentioned terms, the impact of disturbances was projected in accordance with likely prices on domestic and foreign property market, as well as probable conditions and quality of business environment. In the considered situation, the set $B$ of tranches $b_{i}$ may be disturbed by relevant set $E^{b}$ of disturbances $e_{i, j}$, $E^{b}=\left\{e_{i, j}: i=1,2, \ldots, i^{b}, j=1,2, \ldots, j^{b}\right\}$. In the result, revenues $D_{i}$ paid in tranches $b_{i}$ may randomly change. In the analyzed case, the sets $E^{b}$ as well as disturbances $e_{i, j}$ that belong to them are relatively independent of each other. Each set $E^{b}$ of disturbances $e_{i, j}$ correspond with a particular tranche $b_{i}$. This means that the execution of each tranche $b_{i} \in B$ may be randomly affected by each threat $e_{i, j} \in E^{b}$.

For the residential housing development sets $E^{b}=\left\{e_{i, j}: i=\overline{1,4}, j=\overline{1,5}\right\}$, of disturbances $e_{i, j}$ related to sets $B=\left\{b_{i}: i=\overline{1,4}\right\}$ of tranches $b_{i}$, values have been identified as follows:

1. Price decline of apartments $j=1$ :

- direct decrease of revenues.

2. Decline (slack) in sale of apartments $j=2$ :

- increase of interest costs and rise of loan repayment;

- possible disruptions of accounting liquidity and rise of various activities costs.

3. Slackening in sale of apartments $j=3$ :

- additional cost of maintenance of unsold apartments (at the expense of the developer).

4. Tighter credit policies by banks (financial restriction of investment) $j=4$ :

- increase of interest costs and rise of loan repayment;

- possible disruptions of accounting liquidity and rise of various activities costs.

5. Changing of economic and business conditions and deterioration of payment terms $j=5$ :

- $\quad$ possible direct changes of any costs of employment, core workers and auxiliary workers, work of machines, and auxiliary equipment, as well as goods and services. 
The random disturbances of costs and revenues reflect the influence of likely conditions of tasks execution and tranches payment. In the various random situations, disturbances can arise with different probabilities, and they can have distinct severity on the project implementation (see Ding, L., Zhou, Y., Akinci, B., 2014 [21]). This means that random implementation conditions directly decide the probability of occurrence $r_{i, j}$ and severity $c_{i, j}$ of disturbances $e_{i, j}$. Disturbances of costs $e_{i, j}, i=1,2, \ldots, i^{s}, j=1,2, \ldots, j^{s}$ that belong to the subsets $E^{S}$, or disturbances $e_{i, j}, i=1,2, \ldots, i^{a}, j=1,2, \ldots, j^{i}$ that belong to the set $E$, may emerge with probability $r_{i, j} \in[0,1]$ and severity $c_{i, j}[0,1]$, and they may variously impact the execution of tasks $a_{i} \in A$. The disturbances of revenues $e_{i, j}$, $i=1,2, \ldots, i^{b}, j=1,2, \ldots, j^{b}$, or $j=1,2, \ldots, j^{i}$ that belong to the set $E^{b}$ may emerge with probability $r_{i, j} \in[0,1]$ and severity $c_{i, j}[0,1]$ and may variously impact payment of tranches $b_{i} \in B$. The probability and severity of the disturbances for costs and revenues of the residential housing development should be estimated by construction and financial experts based on their knowledge, experience, and even intuition. Based on that evaluation, the influences of disturbances on project costs and revenues can be estimated. Depending on values of the disturbances' probability and severity, costs of task execution and revenues paid in tranches may change in varying degree. Degree of average random changes of costs and revenues can be estimated by the use of probabilistic coefficients of optimism and probabilistic coefficients of pessimism for costs and revenues, respectively. The probabilistic coefficients of cost optimism $\underline{p}_{i^{\prime}} i=1,2, \ldots, i^{a}$ reflect likely decreased costs $K_{i}$ of tasks $a_{i} \in A$ due to the probable improvement of implementation conditions. The probabilistic coefficients of costs pessimism $\bar{p}_{i}, i=1,2, \ldots, i^{a}$ reflect likely increased costs $K_{i}$ of tasks $a_{i} \in A$ due to the probable degradation of implementation conditions. Average random impact of disturbances $e_{i, j}, i=1,2, \ldots, i^{a}, j=1,2, \ldots, j^{i}$ on costs $K_{i}$ of tasks $a_{i} \in A$ can be calculated by using formulas:

1. Average probability $r_{i}$, and average severity $c_{i}$ of disturbances $e_{i, j} \in E, i=1,2, \ldots, i^{a}$, $j=1,2 \ldots, j^{i}$, which may randomly change costs $K_{i} \in \mathcal{K}$ of the implementation of tasks $a_{i} \in A$ :

$$
r_{i}=\left(\sum_{j=1}^{j=j^{i}} r_{i, j}\right)\left(j^{i}\right)^{-1} ; \quad c_{i}=\left(\sum_{j=1}^{j=j^{i}} c_{i, j}\right)\left(j^{i}\right)^{-1}
$$

2. Probabilistic coefficients of cost optimism $\underline{p}_{i} \in[0,1]$ and cost pessimism $\bar{p}_{i} \in[0,1]$, $i=1,2, \ldots, i^{a}$ :

$$
\underline{p}_{i}=1-r_{i} c_{i} ; \quad \bar{p}_{i}=1-\left(1-r_{i}\right)\left(1-c_{i}\right)
$$

- $\quad$ coefficients $p_{i}=1$ indicate extremely favorable conditions for carrying out tasks $a_{i} \in A$ and possible maximum reduction of cost $K_{i} \in \mathcal{K}$ and $\underline{p}_{i}=0$ points of an opposite case;

- $\quad$ coefficients $\bar{p}_{i}=1$ indicate extremely difficult conditions for carrying out tasks $a_{i} \in A$ and possible maximum increase of costs $K_{i} \in \mathcal{K}$ and $\bar{p}_{i}=0$ points of an opposite case.

Similarly, the probabilistic coefficients of revenue optimism $\bar{p}_{i} i=1,2, \ldots, i^{b}$ reflect the likely increase of revenues $D_{i}$ paid in tranches $b_{i} \in B$ due to the probable improvement of business and payment conditions. The probabilistic coefficients of revenue pessimism $p_{i}, i=1,2, \ldots, i^{b}$ reflect the likely decrease of revenues $D_{i}$ paid in tranches $b_{i} \in B$ due to

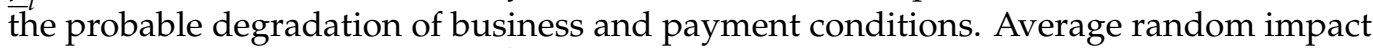
of disturbances $e_{i, j}, i=1,2, \ldots, i^{b}, j=1,2, \ldots, j^{i}$ on revenues tranches $D_{i}$ payment can be calculated by using formulas:

$$
r_{i}=\left(\sum_{j=1}^{j=j^{i}} r_{i, j}\right)\left(j^{i}\right)^{-1} ; \quad c_{i}=\left(\sum_{z=1}^{j=j^{i}} c_{i, j}\right)\left(j^{i}\right)^{-1}
$$


1. Probabilistic coefficients of revenue pessimism $\underline{p}_{i}=[0,1]$ and revenue optimism $\bar{p}_{i}=[0,1], i=1,2, \ldots, i^{b}$ :

$$
\underline{p}_{i}=1-\left(1-r_{i}\right)\left(1-c_{i}\right) ; \quad \bar{p}_{i}=1-r_{i} c_{i}
$$

- the coefficient $p_{i}=1$ indicates extremely difficult conditions for carrying out tranches $b_{i} \in B$ payments and possible maximum decrease of revenues $D_{i} \in \mathcal{D}$ and $p_{i}=0$ points of an opposite case;

- $\quad$ the coefficient $\bar{p}_{i}=1$ indicates extremely favorable conditions for carrying out tranches $b_{i} \in B$ payments and possible maximum increase of revenues and $\bar{p}_{i}=0$ points of an opposite case.

Data depicted above allow comprehensively described conditions of the project implementation. In case of the residential housing development costs, the probability $r_{i, j}$ and severity $c_{i, j}$ as well as coefficients of optimism $\underline{p}_{i}$ and pessimism $\bar{p}_{i}$ have been estimated for all disturbances $e_{i, j}$ that may disrupt execution of tasks $a_{i}$ that is for $s=1,2,3,4, i=\overline{1,22}$ and $j=\overline{1,6^{1}}, j=\overline{1,5^{2}}, j=\overline{1,5^{3}}, j=\overline{1,5^{4}}$. For the residential housing development revenues, the probability $r_{i, j}$ and severity $c_{i, j}$, as well as coefficients of optimism $\underline{p}_{i}$ and pessimism $\bar{p}_{i}$, have been estimated for all disturbances $e_{i, j}$ that may disrupt payment of tranches $b_{i}$ that is for $i=\overline{1,4}$ and $j=\overline{1,5}$.

Random factors of optimism and pessimism of costs and revenues allow for comprehensive randomization of the primary initial data and thus take into account the impact of disturbances on the course and results of the project implementation.

\subsubsection{Randomized Costs of Tasks and Revenues of Tranches}

In reality, costs of task execution and revenue tranches payment are random variables of costs of carrying out tasks and random variables of revenue tranches payment. Such quantities (see, e.g., Benjamin, J. R. and Cornell, C. A. 2014 [24]) should be described by means of appropriate probability density functions or probability distribution functions. Unfortunately, these functions in an analyzed situation are unknown or are virtually impossible to directly elaborate. In that case, probabilistic characteristic of costs and revenues as random variables have been developed by the use of the data randomization method. With this end in view, values of primary initial costs $K_{i}, i=1,2, \ldots, i^{a}$ and primary initial revenues $D_{i}, i=1,2, \ldots, i^{b}$ after additional analysis have been verified as the most probable values of random costs $\hat{K}_{i}, i=1,2, \ldots, i^{a}$ of tasks $a_{i}$ execution and the most probable random revenues $\hat{D}_{i}, i=1,2, \ldots, i^{b}$ paid in tranches $b_{i}$. Next, using coefficients of optimism $\underline{p}_{i}$ and pessimism $\bar{p}_{i}$, the probable bottom boundaries $\underline{K}_{i}$ and the probable upper boundaries $\bar{K}_{i}$ of costs $K_{i}$ of tasks $a_{i}$ have been calculated. Similarly, using coefficients of optimism $\underline{p}_{i}$ and pessimism $\bar{p}_{i}$, the probable bottom boundaries $\underline{D}_{i}$ and the probable upper boundaries $\bar{D}_{i}$ of revenues $D_{i}$ paid in tranches $b_{i}$ have been calculated. Based on these values (see e.g., Hajdu M., Bokor O. 2016 [25]), using PERT-beta probability distribution function and simplified formulas, the expected values $E\left[K_{i}\right], i=1,2, \ldots, i^{a}$, of random variables of costs $K_{i}$ and the expected values $E\left[D_{i}\right], i=1,2, \ldots, i^{b}$, of random variables of revenues $D_{i}$ can be calculated reliably enough for practice. These values, for the residential housing development, have been estimated as follows:

1. The most probable costs $\hat{K}_{i}, i=\overline{1,22}$, of tasks $a_{i}$ execution-primary initial costs verified by experts due to the predicted random implementation conditions.

2. Probable bottom boundaries of costs $\underline{K}_{i}=\hat{K}_{i}-p_{i} \hat{K}_{i}, i=\overline{1,22}$ of tasks $a_{i}$ execution.

3. Probable upper boundaries of costs $\bar{K}_{i}=\hat{K}_{i}+\bar{p}_{i} \hat{K}_{i}, i=\overline{1,22}$ of tasks $a_{i}$ execution.

4. Expected costs $E\left[K_{i}\right], i=\overline{1,22}$ of tasks $a_{i}$ execution:

$$
E\left[K_{i}\right]=\frac{\underline{K}_{i}+4 \hat{K}_{i}+\bar{K}_{i}}{6}
$$


5. Variance of costs $\sigma^{2}\left[K_{i}\right], i=\overline{1,22}$ of tasks $a_{i}$ execution:

$$
\sigma^{2}\left[K_{i}\right]=\left(\frac{\bar{K}_{i}-\underline{K}_{i}}{6}\right)^{2}
$$

6. The most probable revenues $\hat{D}_{i}, i=1,2,3,4$, paid in tranches $b_{i}$-primary initial revenues verified by experts due to the predicted random implementation conditions.

7. Probable bottom boundaries of revenues $\underline{D}_{i}=\hat{D}_{i}-\underline{p}_{i} \hat{D}_{i}, i=1,2,3,4$, paid in tranches $b_{i}$.

8. Probable upper boundaries of revenues $\bar{D}_{i}=\hat{D}_{i}+\bar{p}_{i} \hat{D}_{i}, i=1,2,3,4$, paid in tranches $b_{i}$.

9. Expected revenues $E\left[D_{i}\right], i=1,2,3,4$, paid in tranches $b_{i}$ :

$$
E\left[D_{i}\right]=\frac{\underline{D}_{i}+4 \hat{D}_{i}+\bar{D}_{i}}{6}
$$

10. Variance of revenues $\sigma^{2}\left[D_{i}\right], i=1,2,3,4$, paid in tranches $b_{i}$ :

$$
\sigma^{2}\left[D_{i}\right]=\left(\frac{\bar{D}_{i}-\underline{D}_{i}}{6}\right)^{2}
$$

Estimated in this way, values of the quantities were used for calculations of the randomized project total cost and overall revenue.

\subsubsection{Randomized Total Cost and Overall Revenue of the Residential Housing} Development

The total cost and overall revenue of the residential housing development are random variables. The random variable of project total cost $K$ is equal to the sum of cost random variables $K_{i}, i=1,2, \ldots, i^{a}$ of tasks $a_{i}$ execution. Alike, the random variable of project overall revenue $D$ is equal the sum of revenue random variables $D_{i}, i=1,2, \ldots, i^{b}$ paid in tranches $b_{i}$. The values of random total cost, among others, depend on the dependence between the added random variables $K_{i}$. The values of random overall revenue, among others, depend on dependence between the analyzed random variables $D_{i}$. Taking into account rules and a way of tasks execution and tranches payment, one can confirm that individual tasks are executed and particular tranches are paid relatively independently of each other. They are physically relatively independent of each other. So, one can conclude that random variables $K_{i}, i=1,2, \ldots, i^{a}$ and random variables $D_{i}, i=1,2, \ldots, i^{b}$ are independent and uncorrelated. These variables also take nonzero values. In this case, the project total expected cost $E[K]$ is the sum of expected tasks costs $E\left[K_{i}\right], i=1,2, \ldots, i^{a}$ incurred on an execution of all project tasks $a_{i} \in A$. Similarly, the project overall expected revenue $E[D]$ is the sum of expected revenues $E\left[D_{i}\right], i=1,2, \ldots, i^{b}$ paid in all project tranches $b_{i} \in B$. For the residential housing development, these quantities can be estimated as follows:

1. Expected value of the project total cost $E[K]$ :

$$
E[K]=\sum_{i=1}^{i=22} E\left[K_{i}\right]
$$

2. Variance of the project total $\operatorname{cost} \sigma^{2}[K]$ :

$$
E[K]=\sum_{i=1}^{i=22} E\left[K_{i}\right]
$$


3. Expected value of the project overall revenue $E[D]$ :

$$
E[D]=\sum_{i=1}^{4} E\left[D_{i}\right]
$$

4. Variance of the overall project revenue $\sigma^{2}[D]$ :

$$
[D]=\sum_{i=1}^{4} \sigma^{2}\left[D_{i}\right]
$$

Randomized data of costs and revenues of the residential housing development implementation have been tallied in Tables 3 and 4 in Results section, respectively.

\begin{tabular}{|c|c|c|c|c|c|c|c|c|}
\hline$s$ & $a_{i} \in A^{s}$ & $a_{i} \in A$ & $E\left[K_{i}\right]$ & $K_{i}$ & $\hat{K}_{i}$ & $\overline{K_{i}}$ & $p_{i}$ & $\overline{p_{i}}$ \\
\hline \multirow{6}{*}{$s 1$} & $a_{1}$ & $a_{1}$ & 98,379 & 24,888 & 98,242 & 172,415 & 0.75 & 0.76 \\
\hline & $a_{2}$ & $a_{2}$ & $11,966,298$ & $2,676,893$ & $12,083,779$ & $20,785,778$ & 0.78 & 0.72 \\
\hline & $a_{3}$ & $a_{3}$ & $3,371,615$ & 670,741 & $3,438,474$ & $5,805,051$ & 0.80 & 0.69 \\
\hline & $a_{4}$ & $a_{4}$ & $6,252,564$ & $1,467,082$ & $6,287,495$ & $10,898,324$ & 0.77 & 0.73 \\
\hline & $a_{5}$ & $a_{5}$ & $3,312,396$ & 753,640 & $3,340,232$ & $5,759,812$ & 0.77 & 0.72 \\
\hline & & Sum & $25,001,252$ & & & & & \\
\hline \multirow{7}{*}{$s 2$} & $a_{1}$ & $a_{6}$ & 184,487 & 35,565 & 188,573 & 317,067 & 0.81 & 0.68 \\
\hline & $a_{2}$ & $a_{7}$ & 185,745 & 38,808 & 188,573 & 321,366 & 0.79 & 0.70 \\
\hline & $a_{3}$ & $a_{8}$ & 185,745 & 38,469 & 188,573 & 321,706 & 0.80 & 0.71 \\
\hline & $a_{4}$ & $a_{9}$ & 554,405 & 109,297 & 565,720 & 954,256 & 0.81 & 0.69 \\
\hline & $a_{5}$ & $a_{10}$ & 557,234 & 115,973 & 565,720 & 964,552 & 0.80 & 0.71 \\
\hline & $a_{6}$ & $a_{11}$ & 185,745 & 38,469 & 188,573 & 321,706 & 0.80 & 0.71 \\
\hline & & Sum & $1,853,360$ & & & & & \\
\hline \multirow{9}{*}{ s3 } & $a_{1}$ & $a_{12}$ & 174,540 & 34,671 & 177,799 & 301,370 & 0.81 & 0.70 \\
\hline & $a_{2}$ & $a_{13}$ & $9,210,002$ & $1,941,568$ & $9,334,462$ & $15,980,599$ & 0.79 & 0.71 \\
\hline & $a_{3}$ & $a_{14}$ & $3,054,443$ & 609,852 & $3,111,487$ & $5,270,859$ & 0.80 & 0.69 \\
\hline & $a_{4}$ & $a_{15}$ & $14,350,624$ & $2,745,932$ & $14,668,440$ & $24,684,051$ & 0.81 & 0.68 \\
\hline & $a_{5}$ & $a_{16}$ & $3,070,001$ & 653,412 & $3,111,487$ & $5,320,643$ & 0.79 & 0.71 \\
\hline & $a_{6}$ & $a_{17}$ & $3,470,568$ & 752,171 & $3,511,536$ & $6,025,093$ & 0.79 & 0.72 \\
\hline & $a_{7}$ & $a_{18}$ & 872,698 & 174,954 & 888,996 & $1,505,249$ & 0.80 & 0.69 \\
\hline & $a_{8}$ & $a_{19}$ & 436,349 & 87,477 & 444,498 & 752,624 & 0.80 & 0.69 \\
\hline & & Sum & $34,639,225$ & & & & & \\
\hline \multirow{4}{*}{$s 4$} & $a_{1}$ & $a_{20}$ & 85,936 & 14,188 & 88,900 & 145,831 & 0.84 & 0.64 \\
\hline & $a_{2}$ & $a_{21}$ & 152,267 & 23,978 & 158,063 & 257,374 & 0.85 & 0.63 \\
\hline & $a_{3}$ & $a_{22}$ & 120,207 & 22,266 & 123,289 & 205,819 & 0.82 & 0.67 \\
\hline & & $\operatorname{Sum} E[K]$ & $\begin{array}{c}358,410 \\
61,852,242\end{array}$ & & & & & \\
\hline
\end{tabular}

Table 3. Randomized data of costs.

Table 4. Randomized data of revenues.

\begin{tabular}{cccccccc}
\hline Revenue & $\boldsymbol{b}_{\boldsymbol{i}} \in \boldsymbol{B}$ & $\boldsymbol{E}\left[\boldsymbol{D}_{\boldsymbol{i}}\right]$ & $\underline{\boldsymbol{D}}_{\boldsymbol{i}}$ & $\hat{\boldsymbol{D}}_{\boldsymbol{i}}$ & $\overline{\boldsymbol{D}_{\boldsymbol{i}}}$ & $\underline{\boldsymbol{p}}_{\boldsymbol{i}}$ & $\overline{\boldsymbol{p}_{\boldsymbol{i}}}$ \\
\hline \multirow{5}{*}{ Tranches } & $b_{1}$ & $8,943,077$ & 799,297 & $9,867,860$ & $13,387,725$ & 0.92 & 0.36 \\
& $b_{2}$ & $51,734,858$ & $5,436,555$ & $56,630,778$ & $78,449,484$ & 0.90 & 0.39 \\
& $b_{3}$ & $4,611,152$ & 302,699 & $5,095,948$ & $6,980,419$ & 0.94 & 0.37 \\
\cline { 2 - 8 } & $b_{4}$ & $3,138,317$ & 208,179 & $3,504,697$ & $4,602,936$ & 0.94 & 0.31 \\
\cline { 2 - 8 } & \multirow{2}{*}{$\mathrm{Sum} E[D]$} & $68,427,404$ & $68,427,404$ & & & & \\
\hline
\end{tabular}


Calculated in the above way, the expected total cost $E[K]$ and the expected overall revenue $E[D]$ represent only a particular possible case. This means that values $E[K]$ and $E[D]$ describe only this one case of the project implementation. The range of probable changings of these values is interesting. These variations were measured by using coefficients of the risk of total $\operatorname{cost} p(k)$ and the risk of overall revenue $p(d)$. Values of these quantities were calculated assuming student's t-distribution functions for the random variable $E[K]$ of total cost and for the random variable $E[D]$ of overall revenue. In accordance with the results of comprehensive analysis, the risk measure of total cost is the probability $p(k)$ that the actual total cost $\mathcal{K}=E(K)$ of the project is lesser than $\mathrm{k}$. The risk measure of overall revenue is the probability $p(d)$ that the actual overall revenue $\mathcal{D}=E(D)$ of the project is greater than $\mathrm{d}$. Values of $p(k)$ and $p(d)$, according to the comparative values $\mathrm{k}$ and $\mathrm{d}$, can be calculated as follows:

1. Cost risk (contingency) of the project $p(k)$ :

$$
p(k)=P[E(K) \leq k]=Z\left[\frac{k-E(K)}{\sqrt{\sigma^{2}(K)}}\right] ; \quad p(k) \in[0,1]
$$

$p(k)$-means probability that the real total cost $\mathcal{K}=E(K)$ should be less than $k$.

2. Revenue risk (contingency) of the project $p(d)$ :

$$
p(d)=P[E(D) \geq d]=1-P[E(D) \leq d]=Z\left[\frac{d-E(D)}{\sqrt{\sigma^{2}(D)}}\right] ; \quad p(d) \in[1,0]
$$

$p(d)$-means probability that the real overall revenue $\mathcal{D}=E(D)$ should be greater than $d$.

Changes of the cost risk $p(k)$ depending on comparative costs $k$ and changes of the revenue risk $p(d)$ depending on comparative revenues $d$ are presented in Figure 1 in the Results section.

Classical and well-known estimation of the net present value was presented in many publications, e.g., Gorlewski, B. 2015 [17], JASPERS. 2008 [19], and Skov N. W. 1994 [26]. Unfortunately, classical approaches do not sufficiently allow the consideration of random conditions of the project implementation. This is possible in the proposed method. The net present value of the residential housing development efficiency has been estimated as a random variable equal to a quotient of the random variable of project overall revenue and random variable of project total cost. The values of such quotient function one can estimate using an appropriate derived probability density function of quotient of these two random variables. Unfortunately, such function is unknown and, in practice, impossible to define. Fortunately, the random variable of expected value of the project overall revenue and the random variable of expected value of the project total cost are independent, uncorrelated, and take positive and nonzero values. When abovementioned conditions are fulfilled, an expected value of a quotient of two random variables, as it has been proved by Frishman, F. in 1971 [27], is equal to a quotient of expected values of these random variables. Therefore, based on the randomized data, the net present value of the residential housing development efficiency has been estimated as follows [28]:

1. Net present value of the residential housing development efficiency (NPE):

$$
N P E=E\left[\frac{D}{K}\right]=\frac{E[D]}{E[K]} \text {, provided that } E(K) \neq 0
$$

2. Variance of efficiency:

$$
\operatorname{Var}(N P E)=\operatorname{Var}\left[\frac{D}{K}\right]=\frac{\operatorname{Var}(D) *[E(K)]^{2}-\operatorname{Var}(K) *[E(D)]^{2}}{[E(K)]^{2} *\left\{\operatorname{Var}(K)+[E(K)]^{2}\right\}}
$$


3. Standard deviation of efficiency:

$$
\sigma(N P E)=\sqrt{\sigma^{2}(R P E)}
$$

4. $\quad$ Expected gross profit $E[Z]$ :

$$
E[Z]=E[D-K]=E[D]-E[K]
$$

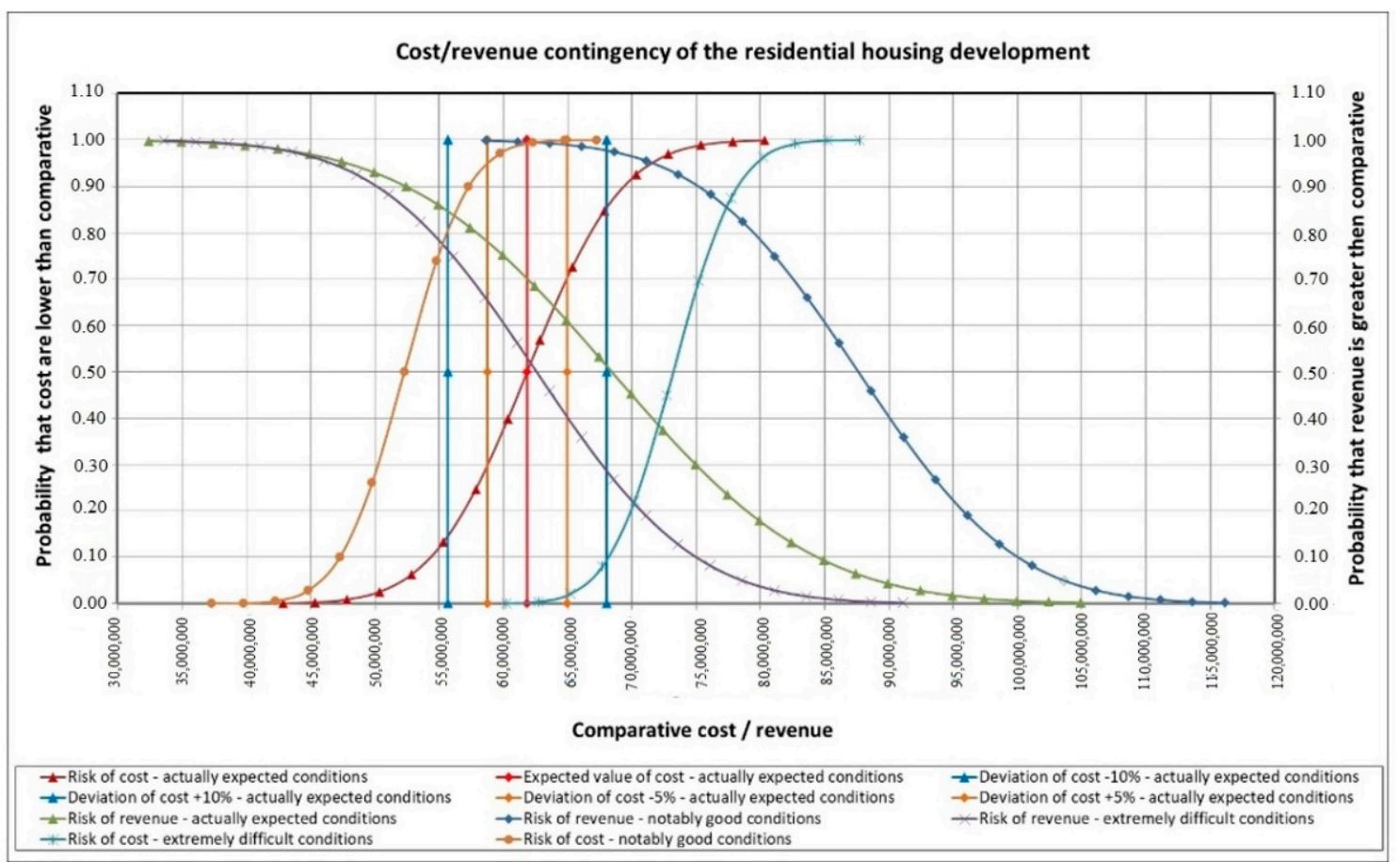

Figure 1. Comparative risk characterization of the costs and revenues of the residential housing development 1 .

\section{Results}

The primary initial data of the residential housing development implementation 1 for costs have been listed in Table 1 and for revenues in Table 2.

Randomized data of costs and revenues of the residential housing development 1 implementation have been tallied in Tables 3 and 4, respectively.

Changes of the cost risk $p(k)$, depending on comparative costs $\mathrm{k}$, and changes of the revenue risk $p(d)$, depending on comparative revenues $d$, are presented in Figure 1 .

In the charts, the risk of total cost $p(k)$ and of the risk of overall revenue $p(d)$ have been presented for notably good, actually expected, and extremely difficult project implementation conditions. Coefficients of the risk of total cost $p(k)$ vary in the range of $[0,1]$. The coefficients of risk $p(k)=0$ are indicated by minimum costs $\underline{k}$, which amounts to 39,794,092 PLN for notably good conditions, 45,352,247 PLN for actually expected conditions, and 62,711,729 PLN for extremely difficult conditions. This means that the actual cost $\mathcal{K}$ of the project implementation should not be less than $\underline{k}$. Coefficients of risk $p(k)=1$ are indicated by maximum costs $\bar{k}$, which amount to $64,794,092$ PLN for notably good conditions, 77,852,247 PLN for actually expected conditions, and 85,211,729 PLN for extremely difficult conditions. This means that the actual cost $\mathcal{K}$ of the project implementation should be less than $\bar{k}$.

Coefficients of the risk of overall revenue $p(d)$ vary in the range of $[0,1]$. Coefficients of risk $p(k)=1$ are indicated by minimum revenue $\underline{d}$, which amount to $61,115,830$

PLN for notably good conditions, 34,927,404 PLN for actually expected conditions, and 36,082,735 PLN for extremely difficult conditions. This means that the actual revenue 
$\mathcal{D}$ of the project implementation should be greater than $\underline{d}$. Coefficients of risk $p(d)=0$ are indicated by maximum revenue $\bar{d}$, which amount to $113,615,830$ PLN for notably good conditions, 102,427,404 PLN for actually expected conditions, and 88,582,735 PLN for extremely difficult conditions. This means that the actual revenue $\mathcal{D}$ of the implementation should not be greater than $\underline{d}$.

Final results of the net present value of the residential housing development efficiency have been tallied in Table 5 .

Table 5. Final results for conditions initially planned, actually expected, and really occurred for investment 1 .

\begin{tabular}{|c|c|c|c|}
\hline & Primary Initial Data & Prediction for Risk Conditions & Real Conditions ex Post \\
\hline & Notably good conditions of property sale & Complicated conditions of property sale & Complicated conditions of property sale \\
\hline & $\begin{array}{l}\text { Notably good conditions at labor and } \\
\text { construction products market }\end{array}$ & $\begin{array}{l}\text { Extremely difficult conditions at labor } \\
\text { and construction products market }\end{array}$ & $\begin{array}{l}\text { Extremely difficult conditions at labor } \\
\text { and construction products market }\end{array}$ \\
\hline Specification & Primary value & Calculated value & Realized value \\
\hline \multicolumn{4}{|c|}{ Expected conditions $(0, x x)$} \\
\hline Revenue & $90,300,000$ & $68,534,790$ & $66,990,000$ \\
\hline Cost & $67,800,000$ & $61,743,054$ & $60,939,000$ \\
\hline Efficiency & 1.33 & 1.11 & 1.10 \\
\hline Gross profit & $22,500,000$ & $6,791,736$ & $6,051,000$ \\
\hline \multicolumn{4}{|c|}{ Notably good conditions $(0,00)$} \\
\hline Revenue & & $87,853,537$ & \\
\hline Cost & & $52,293,772$ & \\
\hline Efficiency & & 1.68 & \\
\hline Gross profit & & $35,559,765$ & \\
\hline \multicolumn{4}{|c|}{ Extremely difficult conditions $(1,00)$} \\
\hline Revenue & & $62,229,589$ & \\
\hline Cost & & $73,211,281$ & \\
\hline Efficiency & & 0.85 & \\
\hline Gross profit & & $-10,981,692$ & \\
\hline
\end{tabular}

On the basis of the final results, the residential housing development efficiency was comprehensively assessed.

In order to present the practical application of the discussed method, the final results for two subsequent construction projects are presented below.

\subsection{Investment 2}

Changes of the cost risk $p(k)$ depending on comparative costs $k$ and changes of the revenue risk $p(d)$, depending on comparative revenues $d$, are presented in the Figure 2. 


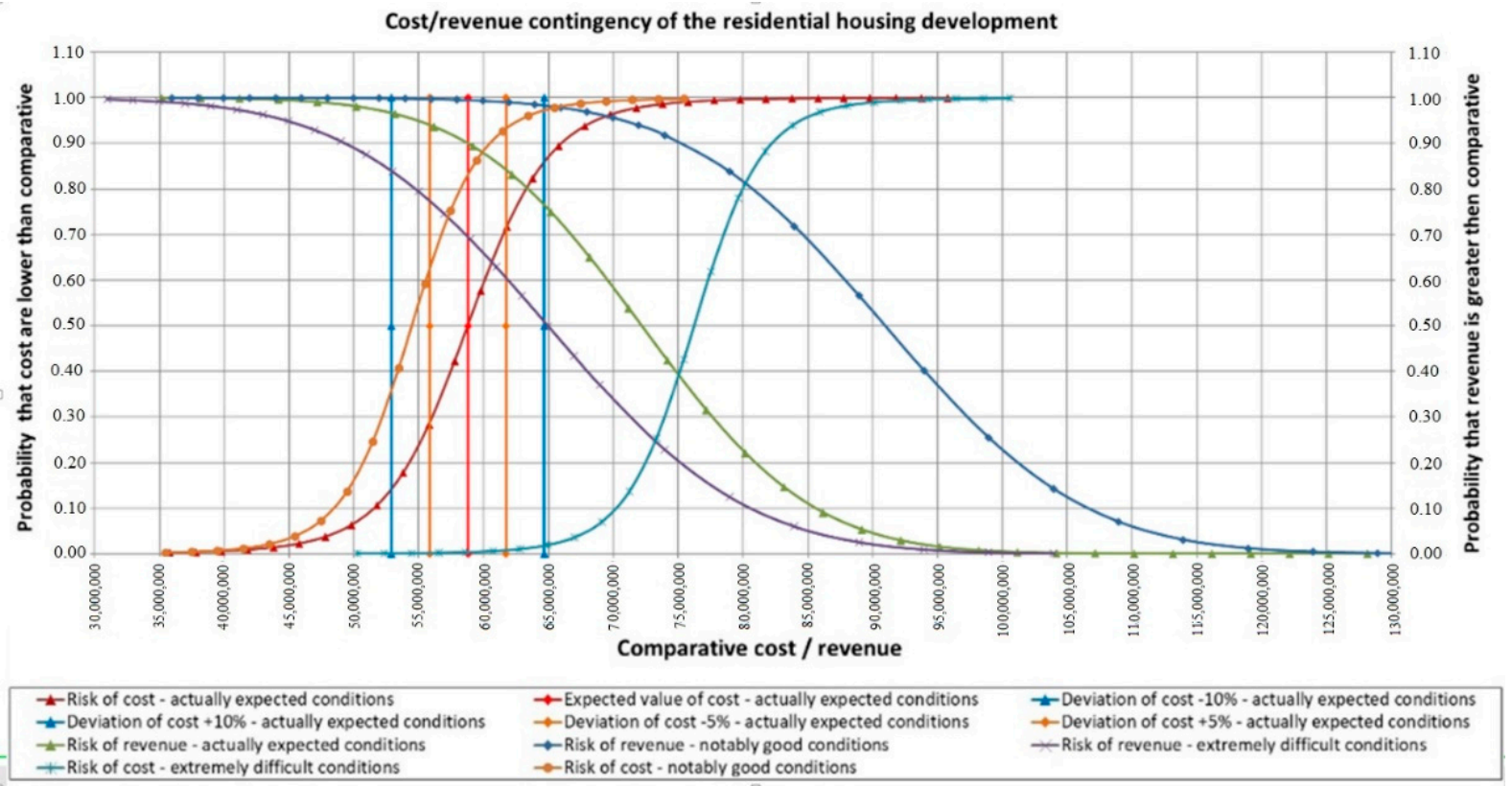

Figure 2. Comparative risk characterization of the costs and revenues of the residential housing development 2.

Final results of the net present value of the residential housing development efficiency have been tallied in the Table 6 .

Table 6. Final results for conditions initially planned, actually expected, and really occurred for investment 2.

\begin{tabular}{cccc}
\hline & Primary Initial Data & Prediction for Risk Conditions & Real Conditions ex Post \\
\hline & $\begin{array}{c}\text { Notably good conditions of property sale } \\
\text { construction products market }\end{array}$ & $\begin{array}{c}\text { Complicated conditions of property sale } \\
\text { and construction products market }\end{array}$ & $\begin{array}{c}\text { Complicated conditions of property sale } \\
\text { and construction products market }\end{array}$ \\
\hline Specification & Primary value & Calculated value & Realized value \\
\hline Revenue & Expected conditions $(0, x x)$ & $69,638,000$ \\
\hline Cost & $87,700,000$ & $72,190,231$ & $56,847,000$ \\
\hline Efficiency & $70,530,000$ & $58,782,084$ & 1.23 \\
\hline Gross profit & 1.24 & 1,23 & $12,791,000$ \\
\hline Revenue & $17,170,000$ & $13,408,147$ & \\
\hline Cost & & Notably good conditions $(0,00)$ & \\
\hline Efficiency & $90,959,144$ & \\
\hline Gross profit & $54,454,291$ & \\
\hline Revenue & 1.67 & \\
\hline Cost & Extremely difficult conditions $(1,00)$ & \\
\hline Efficiency & $64,970,817$ & \\
\hline Gross profit & $76,236,008$ & \\
\hline
\end{tabular}

On the basis of the final results, the residential housing development efficiency has been comprehensively assessed. 


\subsection{Investment 3}

Changes of the cost risk $p(k)$ depending on comparative costs $k$ and changes of the revenue risk $p(d)$, depending on comparative revenues $d$, are presented in the Figure 3.

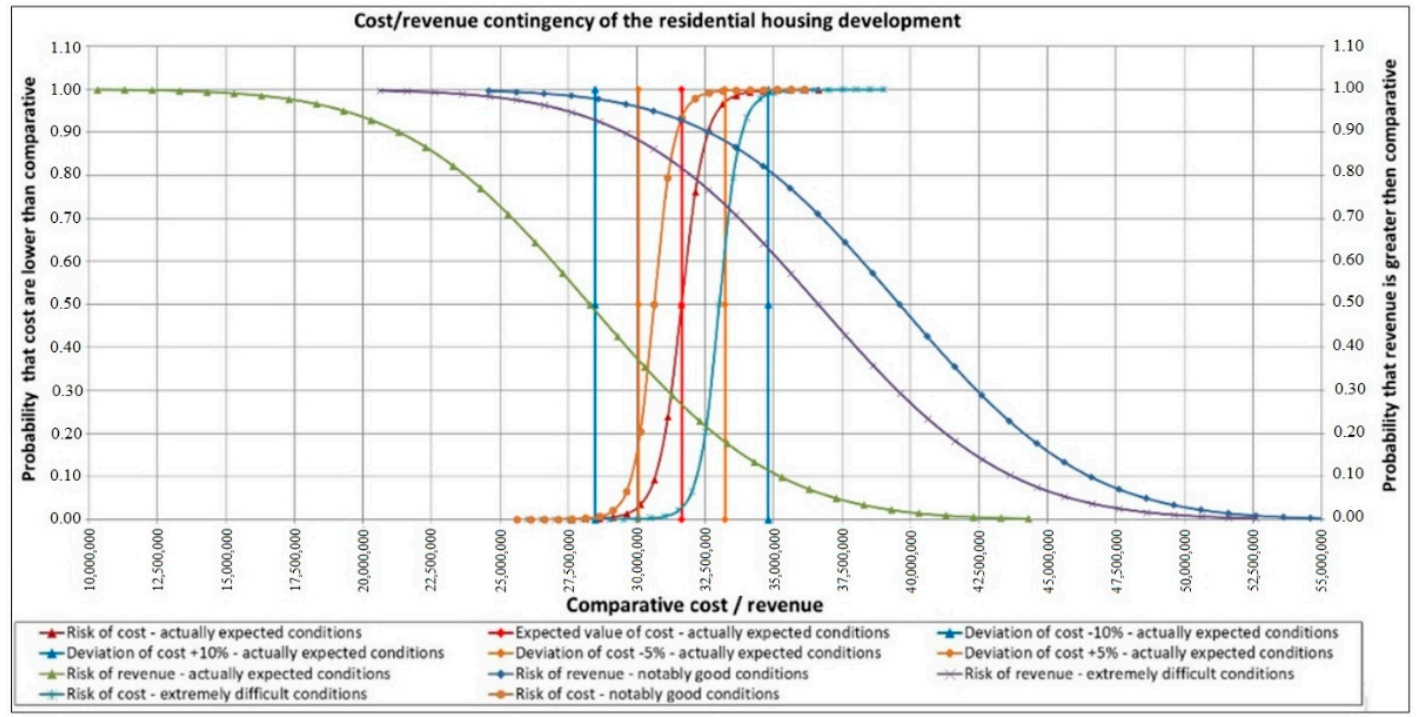

Figure 3. Comparative risk characterization of the costs and revenues of the residential housing development 3.

Final results of the net present value of the residential housing development efficiency have been tallied in Table 7.

Table 7. Final results for conditions initially planned, actually expected, and really occurred for investment 3.

\begin{tabular}{|c|c|c|c|}
\hline & Primary Initial Data & Prediction for Risk Conditions & Real Conditions ex Post \\
\hline & Notably good conditions of property sale & Complicated conditions of property sale & Complicated conditions of property sale \\
\hline & $\begin{array}{l}\text { Notably good conditions at labor and } \\
\text { construction products market }\end{array}$ & $\begin{array}{l}\text { Extremely difficult conditions at labor } \\
\text { and construction products market }\end{array}$ & $\begin{array}{l}\text { Extremely difficult conditions at labor } \\
\text { and construction products market }\end{array}$ \\
\hline Specification & Primary value & Calculated value & Realized value \\
\hline \multicolumn{4}{|c|}{ Expected conditions $(0, x x)$} \\
\hline Revenue & $38,190,000$ & $36,631,885$ & $40,585,000$ \\
\hline Cost & $32,500,000$ & $31,641,704$ & $34,591,000$ \\
\hline Efficiency & 1.18 & 1.16 & 1.17 \\
\hline Gross profit & $5,690,000$ & $4,990,181$ & $5,994,000$ \\
\hline \multicolumn{4}{|l|}{$\begin{array}{l}\text { Notably } \\
\text { good } \\
\text { conditions } \\
(0,00)\end{array}$} \\
\hline Revenue & & $39,609,233$ & \\
\hline Cost & & $30,632,977$ & \\
\hline Efficiency & & 1.29 & \\
\hline Gross profit & & $8,976,255$ & \\
\hline \multicolumn{4}{|c|}{ Extremely difficult conditions $(1,00)$} \\
\hline Revenue & & $28,292,309$ & \\
\hline Cost & & $33,016,968$ & \\
\hline Efficiency & & 0.86 & \\
\hline Gross profit & & $-4,724,659$ & \\
\hline
\end{tabular}


On the basis of the final results, the residential housing development efficiency has been comprehensively assessed.

The table with the final results for each of the analyzed investments summarizes and compares the final expected values, such as revenue, cost, efficiency, or gross profit, calculated using the ex-ante method. The table also lists the theoretically possible extreme values between which the expected values are. Particularly good conditions, i.e., maximum income at minimum costs, and extremely difficult conditions, i.e., minimum income at maximum costs.

A graphic image of the above values is presented in the graph. The curves of the expected costs and revenues are located between the extreme, minimum, and maximum costs and revenue curves.

The risk chart of the total cost and total revenue from the implementation of residential investments is constructed in the following structure: the abscissa is the values for costs and revenues, respectively. The ordinate axis in the left-hand system is the probability values that the corresponding costs will be lower than the comparative costs, and the right-hand side is that the probability values of revenues will be higher than the comparative ones. This layout allows you to summarize all cost and revenue curves on one chart.

The expected values of costs and revenues correspond to the ordinate of 0.5 .

Above and below the ordinate 0.5 , we obtain the reading of the probability occurrence value and the corresponding costs and revenues. In such a system, the slope of the curves makes it possible to assess the speed of changes in the probability of threats, depending on possible changes in costs and revenues.

\section{Discussion}

In analyzed cases, the net present value of the residential housing development efficiency has been estimated on the basis of randomized primary initial data and is equal to: for investment 1: 1.11; for investment 2: 1.23; for investment 3: 1.16. The efficiency calculated on the basis of the primary initial data is equal to: for investment 1: 1.33; for investment 2: 1.24; for investment 3: 1.18. The efficiency calculated on the basis of realized data is equal to: for investment 1: 1.10; for investment 2: 1.23; for investment 3: 1.17.

It is easy to see that, in analyzed conditions of the investment 1 implementation, the randomized method of efficiency estimating allows for the determination of the project efficiency close to the actual value that has been calculated on the basis realized data. Such accuracy is especially important and reasonable when disturbances strongly interfere with the project implementation.

On the other hand, the investment 2 is a construction undertaking similar to the investment 1 in terms of size, location, and standard of investment execution. One can risk the statement that these are twin investments that were implemented under extremely different conditions.

The investment 2 was carried out in a period of very good economic conditions on the housing construction market, and particularly good conditions were adopted. The investment was completed successfully, in accordance with all the assumed parameters.

All presented above estimations are considered also for exceptionally possible project implementation conditions. Such an approach allows for the determination of a bottom boundary and top boundary of the net present value of the residential housing development efficiency. The bottom boundary of the net present value of randomized efficiency of the residential housing development is estimated for the notably favorable implementation condition. For the described example, it is equal to, for investment 1: 1.68; for investment 2: 1.67; for investment 3: 1.29. The top boundary value of the efficiency is estimated for extremely difficult implementation conditions. For the described example, it is equal to: for investment 1: 0.85 ; for investment 2: 0.85 ; for investment 3: 0.86 . Such information will certainly be useful in making operational decisions. 


\section{Conclusions}

The method presented in the article complements the publications and studies to date in terms of the probabilistic approach to the issue of assessing the effectiveness of a construction project [29-31]. Three construction projects were subjected to detailed tests: the first—stable and achieved parameters as expected; the second-burdened with a significant loss of stability in the multithreaded aspect; the third-an investment that did not show over-expected deviations from the adopted assumptions. The method proposed in the article, assuming appropriate parameters, has confirmed the effectiveness and correctness of the predicted current net value of probabilistic efficiency (REP). All analyzed investments are real construction projects of the Warsaw developing market. The adopted initial parameters and the obtained final results were verified by the final settlements of the investment. The authors' recommendation is to apply the method to various types and scopes of completed investments, which will enable the development of a broad database for future analyses of new construction projects.

The final result of the method used will be a reliable database that can significantly improve the efficiency, quality, and sustainability requirements of future investments.

Author Contributions: Conceptualization, T.K. and R.W.; methodology, T.K. and A.S.-K.; formal analysis, A.S.-K.; resources, R.W.; data curation, R.W.; writing-original draft preparation, A.S.-K.; writing-review and editing, T.K.; supervision, T.K.; project administration, R.W. All authors have read and agreed to the published version of the manuscript.

Funding: This research received no external funding.

Institutional Review Board Statement: Not applicable.

Informed Consent Statement: Not applicable.

Data Availability Statement: Not applicable.

Conflicts of Interest: The authors declare no conflict of interest. The funders had no role in the design of the study; in the collection, analyses, or interpretation of data; in the writing of the manuscript, or in the decision to publish the results.

\section{References}

1. Biznes, T. Stownik Pojęć Ekonomicznych; Wydawnictwo Naukowe PWN S.A.: Warszawa, Poland, 2007; ISBN 978-83-01-15279-6.

2. Black, J. Słownik Ekonomii; Wydawnictwo Naukowe PWN: Warszawa, Poland, 2008; ISBN 978-83-01-15079-2.

3. Pawłowski, J. Metodyka Oceny Efektywności Finansowej Przedsięwzięć Gospodarczych; Wydawnictwo Uniwersytetu Łódzkiego: Łódź, Poland, 2004; ISBN 83-7171-785-7.

4. Ziarkowski, R. Opcje Rzeczowe Oraz ich Zastosowanie w Formułowaniu i Ocenie Projektów Inwestycyjnych; Wydawnictwo Akademii Ekonomicznej: Katowice, Poland, 2004; ISBN 8372463018 (20+5).

5. Pyszka, A. Istota Efektywności. Definicje i Wymiary; Zeszyty Naukowe Uniwersytetu Ekonomicznego w Katowicach; Uniwersytet Ekonomiczny w Katowicach, Wydział Zarządzania, Katedra Zarządzania Zasobami Ludzkimi, Studia Ekonomiczne: Katowicach, Poland, 2015; ISSN 2083-8611.

6. Pačaiová, H.; Andrejiová, M.; Balažiková, M.; Tomašková, M.; Gazda, T.; Chomová, K.; Hijj, J.; Salaj, L. Methodology for Complex Efficiency Evaluation of Machinery Safety Measures in a Production Organization. Appl. Sci. 2021, 11, 453. [CrossRef]

7. Starczyk-Kołbyk, A.; Kruszka, L. The influence of construction works disturbances on the EVM analysis outcomes-Case study, Archives of Civil Engineering. Arch. Civ. Eng. 2020, 66, 161-177. [CrossRef]

8. Starczyk-Kołbyk, A.; Kruszka, L. Use of the EVM method for analysis of extending the construction project duration as a result of realization disturbances-Case study. Arch. Civ. Eng. 2021, 67, 373-393. [CrossRef]

9. Kasprowicz, T. Inżynieria Przedsięwzięć Budowlanych; Kasprowicz, T., Ed.; Inżynieria Przedsięwzięć Budowlanych, Rekomendowane Metody i Techniki, wyd.; PAN KIWiL, Sekcja IPB: Warszawa, Poland, 2015; pp. 10-20.

10. Kasprowicz, T. Analiza Ryzyka Przedsięwzięć Budowlanych, Budownictwo i Inżynieria Środowiska, Zeszyt 58, nr 3/2011/III; Oficyna Wydawnicza Politechniki Rzeszowskiej: Rzeszów, Poland, 2011; pp. 233-240.

11. Bizon-Górecka, J. O zarządzaniu projektami inwestycyjno-budowlanymi z uwzględnieniem czynników ryzyka. Przegląd Bud. 2008, 79, 42-46.

12. Cao, J.; Song, W. Risk assessment of co-creating value with customers: A rough group analytic network process approach. Expert Syst. Appl. 2016, 55, 145-156. [CrossRef]

13. Radło, M.J. Risk Management in Integrated Management Systems; Warsaw School of Economics: Warsaw, Poland, 2015. 
14. Kalkhoran, S.H.A.; Liravi, G.; Rezagholi, F. Risk Management in Construction Projects. Int. J. Eng. Trends Technol. 2014, 10, 133-138. [CrossRef]

15. Ward, S.C.; Chapman, C.B. Risk-management perspective on the project lifecycle. Int. J. Proj. Manag. 1995, 13/3, 145-149. [CrossRef]

16. Korytárová, J.; Hromádka, V. Risk Assessment of Large-Scale Infrastructure Projects-Assumptions and Context. Appl. Sci. 2021, 11, 109. [CrossRef]

17. Gorlewski, B. Project Effectiveness Evaluation; Warsaw School of Economics: Warsaw, Poland, 2015.

18. Pham, T.Q.D.; Le-Hong, T.; Tran, X.V. Efficient estimation and optimization of building costs using machine learning. Int. J. Constr. Manag. 2021. [CrossRef]

19. JASPERS. Blue Book. Road Infrastructure. Joint Assistance to Support Projects in European Regions; Ministry of Infrastructure: Warsaw, Poland, 2008.

20. De Wilde, P. Building Performance Analysis; John Wiley and Sons Ltd.: Hoboken, NJ, USA, 2018.

21. Ding, L.; Zhou, Y.; Akinci, B. Building Information Modeling (BIM) application framework: The process of expanding from 3D to computable nD. Autom. Constr. 2014, 46, 82. [CrossRef]

22. Halpin, D.W.; Woodhead, R.W. Construction Management, 2nd ed.; John Wiley \& Sons Inc.: New York, NY, USA, 1998.

23. Ritz, G. Total Construction Project Management; McGraw Hill Professional: New York, NY, USA, 1994.

24. Benjamin, J.R.; Cornell, C.A. Probability, Statistics, and Decision for Civil Engineers; Manufactured in the United States by Courier Corporation: New York, NY, USA, 2014.

25. Hajdu, M.; Bokor, O. Sensitivity analysis in PERT networks: Does activity duration distribution matter? Autom. Constr. 2016, 65, 1-8. [CrossRef]

26. Skov, N.W. Finance \& Management; The American Model Applied to Polish Private Enterprise; PRET: Warsaw, Poland, 1994.

27. Frishman, F. On the Arithmetic Means and Variances of Products and Ratios of Random Variables; Army Research Office: Durham, UK, 1971. Available online: https:/ / www.semanticscholar.org/paper/On-the-Arithmetic-Means-and-Variances-ofProducts-Frishman/5116dc6b2987ee3eb26eab0a514c8a4a2e2b953c (accessed on 20 December 2021). [CrossRef]

28. Parmenter, D. Key Performance Indicators: Developing, Implementing, and Using Winning KPIs; Copyright by David Parmenter; John Wiley \& Sons, Inc.: Hoboken, NJ, USA, 2015.

29. Braganca, L.; Kokkari, H.; Veljkovic, M.; Borg, R.P. Sustainable Construction. A Life Cycle Approach in Engineering; International Training School: Hal Far, Malta, 2010.

30. Sicotte, H.; Delerue, H. Project planning, top management support and communication: A trident in search of an explanation. J. Eng. Technol. Manag. 2021, 60, 101626. [CrossRef]

31. Uher, T.E.; Lawson, W. Sustainable development in construction. In Proceedings of the CIB World Building Congress, Gaevle, Sweden, 7-12 June 1998; pp. 1-8. 